\title{
Analysis of Injury Potential of Three-year-old Child Occupants Caused by Inappropriate Installation of Enhanced Child Restraint System with Top Tether in Frontal Crash Accidents
}

\author{
Zhe Wei \\ https://doi.org/10.33976/JERT.8.2/2021/2
}

\begin{abstract}
Objective: Frontal crash accidents remain a significant factor in causing the preventable injury and fatality for child occupants aged 3 in China. Despite the increased public awareness and utilization of child restraint system (CRS), inappropriate installations still exist and lead to a potential to result in injuries of head, thorax and abdomen regions of child occupants, especially when it comes to enhanced child restraint system (ECRS) with top tether. The current study focuses on the influence of top tether upon safety performance of ECRS with top tether in dynamic tests with different set-ups and explores the relationship between inappropriate installation of ECRS with top tether and the injury potential of child occupants aged 3 in a frontal crash. Methods: A testing scheme including 4 dynamic tests was devised to ascertain the extent to which the top tether affected the accelerations of thorax, the abdominal penetration and the head displacements. Different kinds of acceleration curves were employed to conduct the tests and to simulate the real status and situation of child occupants aged 3 in the CRS installed with top tether and without top tether respectively. Parameters of accelerations, abdominal penetrations, and head displacements were measured to analyze quantitatively the influence of inappropriate installations of ECRS with top tether under different conditions. Results: The safety performance of ECRS with the use of top tether was found better than that of ECRS without the use of top tether either in the normal condition or in the extreme condition. The test using the acceleration curves defined by regulations, the accelerations of thorax, abdominal penetrations, and head displacements of P3 manikin in the ECRS with the top tether connected to the anchor point revealed results that all met the requirements. While in the test using acceleration curves of the same kind, and when the top tether was not connected, the parameters measured displayed that the safety performance of the sample was worse than the former one. As for the tests using the more severe acceleration curves defined at will, it was more obvious that top tether could affect the function and safety performance of ECRS greatly, and the functional failure and severe damages occurred to the ECRS without the use of top tether. ECRS with the use of top tether was partly qualified even under the more severe conditions. Conclusions: Inappropriate installation of ECRS such as omitting the step of connecting top tether to anchor point could cause severe injuries and fatalities in frontal crash accidents. Effective measures should be taken to minimize the chances of inappropriate installations of ECRS.
\end{abstract}

Index Terms - Child occupants; Child restraint system; Top tether; Frontal crash; Passive safety

\section{INTRODUCTION}

With the development of economy and due to the construction of infrastructures such as the highways and expressways, car ownership increases rapidly around the world, leading to more and more crash accidents, in which the drivers and passengers suffer from many kinds of injuries directly caused by crashes. In order to reduce or minimize injuries and fatalities from accidents related to automotive crashes, seatbelt was invented to protect the occupants about 60 years ago, and in the 1960s came another invention of child restraint system (CRS) as a passive safety device of a different kind. Child passenger safety is an integral part of child safety [1]. The main aim of CRS is to create a well-anchored seat like that of an adult, safeguarding children to the maximum degree possible in the event of a collision or of abrupt deceleration of the vehicle, by limiting the mobility of the child's body. CRS is oriented to the good protection of child occupants including baby, infants, toddlers and other older children in automotive crashes, since children are more vulnerable to injuries than adults during the collision process [2].

Protecting and improving the safety of children is of fundamental importance. Over the past several decades, dramatic progress has been made in improving the safety and reducing the mortality rate of young child occupants $[3,4]$. However, 
it is still too early to conclude that the problem of child-related traffic safety has been solved. Automotive crashes, until present day, remain one of the leading causes of preventable injury and death for children from newborn to 10 years of age, despite advancement in legislation and public awareness [5, 6]. It is even more urgent to take effective measures to control infant and child mortality brought about by traffic accidents especially in developing countries $[7,8,9]$. Lack of legislation and technical standards accompanied by little knowledge about CRS and child safety has become a big threat to child occupants of vehicles in some places $[10,11]$. In fact, CRS legislation is proven effective to reduce motor vehicle related serious injuries and fatalities $[12,13,14]$. Undoubtedly, what the child occupants and their care-givers can rely upon to prevent the possible injuries must be the CRS's that they are using; because the uncertainty of risks in a severe traffic accident makes it impossible for an adult to react in time and take timely measures in most cases [15].

To a great extent, the effectiveness of CRS depends upon the correct installation of CRS in the vehicle, the appropriate restraining of the child in the CRS, and the appropriate use of CRS [6]. Among the factors that influence the effectiveness related to child occupant's safety closely, the correctness of CRS installation is often neglected or cannot be achieved for the fact that there are various types of CRS and different kinds of installation methods which involve usage of seatbelts, ISOFIX and LATCH, devices seemingly easy to use but inducing the state of user's manipulation at will and regardless of whether the devices designed to restrain the CRS are used in the right way $[16,17]$. When the CRS is equipped with ISOFIX and top tether, the problem mentioned above is more obvious because of many factors [18]. The top tether is not the unique anti-rotation device used for CRS, yet it is the one that is more inclined to be neglected compared to other kinds of devices such as the support leg aiming to achieve the same goal, because it is usually installed in the inconspicuous position and many drivers do not even know about it and how to use it when they carry out the installations of CRS with a top tether [19]. As to enhanced child restraint system used on board of motor vehicles (ECRS), the validity of installation procedure is of great importance. ECRS belongs to one kind of CRS, and has salient features different from general CRS's. Since the CRS equipped with ISOFIX attachment seems easy and convenient to install and use, it has become more and more popular, hence promoting the modification and improvement of the product itself, accompanied by the continuous revision and amendments of technical regulations and standards. Once installed inappropriately, CRS will not bring safety and reliability, but become the source of dangers actually [20]. Accordingly, some research works oriented to the correct installations or use of CRS have been carried out [21,
22, 23]. Regulations and standards related to CRS, nevertheless, serve as an important basis of judgement whether or not the safety device's installation correctness has been ensured.

In Europe, the United Nations Economic Commission for Europe (UNECE) is responsible for the development of vehicle regulations including UN Regulation No. 44 and No.129 which are specific to the requirements and testing methods of CRS. While in China, the national standard of CRS is GB 27887-2011 whose requirements and testing methods of dynamic tests are the same as those of UN Regulation No. 44. However, UN Regulation No. 44 and GB 27887-2011 both undergo adjustments continuously and gradually. From 1st September 2020, no new approvals shall be granted under UN Regulation No.44 to child restraint systems other than Group 3, and from 1st September 2022, no extensions shall be granted under this Regulation to child restraint systems other than Group 3. Obviously, more and more approvals will be granted under Regulation No.129. GB 27887-2011 will be revised similarly to incorporate the same requirements and testing methods of dynamic tests as Regulation No.129. Therefore, no matter in China or in Europe, frontal impact, rear impact and lateral impact tests should all be carried out as part of CRS dynamic tests in the near future. The test procedure specified by the regulation provides an ideal methodology to reproduce or to simulate the abrupt deceleration of vehicle during a crash accident. This paper studies the injury potential of child occupants in a frontal crash, so reproducing the frontal-impact-deceleration curves of the vehicle is necessary by means of a trolley system. Trolley systems can be classified into the deceleration type and the acceleration type, producing the deceleration pulses and acceleration pulses respectively. It is better to choose the acceleration type, for the trolley of this kind can produce the required acceleration curves with higher precision and repeatability [24, 25]. Meanwhile, the deceleration or acceleration curves defined in the regulation can be adopted to carry out the frontal crash test. In order to ensure universality, other proper deceleration or acceleration curves should be defined arbitrarily for the dynamic test.

Parts of the child occupant's body that are prone to injuries could include but not be limited to the head, the thorax and the abdomen which contain all the important organs [26]. Most fatalities are caused by injuries of these parts. According to Findlay, Melucci, Dombrovskiy, Pierre and Lee [27], head/neck injuries are most common for child occupants in all age groups after motor vehicle crashes. Actually, the neck injury or whiplash injury could be avoided when the head has been protected within the safety range, and the head injury is more fatal. If the child occupant's head moves too far from the original place in a crash accident, it may crash into the back of the front seat or other rigid objects and gets wounded 
severely. It is suitable to control the head's displacement because the displacement of the head is bigger than that of the thorax in a frontal crash. As to the thorax, accelerations in 3 dimensions could be the proper criteria to determine whether it is safe for child occupant in the crash, for internal organs in the thorax are quite sensitive to acceleration. There are limits of acceleration to which a human organism can be exposed. And the abdomen as the soft and weak part of the body, should not be subjected to excessive stresses. Meanwhile, the

"Cushion Effect," a phenomenon in which obesity protects against abdominal injury in adults in motor vehicle accidents, is not apparent among pediatric frontal motor vehicle crash victims [28]. Therefore, internal and external structures of child abdomen facilitate penetration of rigid and sharp objects into the soft tissues and organs of human body. So, the abdominal penetration could be taken into consideration for safety evaluation.

Considerable experimental and numerical researches have been conducted to increase the CRS usage rate, to improve the public awareness, to optimize the safety and effectiveness of CRS and so on, with comparatively fewer emphases placed on researches upon assessing the relationship between injury potentials of child occupants and installations of CRS quantitatively by means of experiments $[29,30,31,32]$. Hence, it is necessary to devise a proper scheme for the purpose of discerning and clarifying the relationship mentioned above. Furthermore, how to verify the injury potential of child occupants caused by inappropriate installation of CRS of a certain kind and to explore ways to avoid injuries deserves deep research. As the computer science and computational technology develop rapidly, numerical simulation is more and more widely used in the field of traffic accident analysis [33, 34, 35]. But the methodology of numerical simulation has its own shortcomings and cannot exactly reproduce the crash process without any differences, for it is confined to algorithms and ideal conditions. Instead, the experimental methodology could incorporate more factors into the process and be used for the validation of numerical simulation [36]. Without any limitations, experimental methodology is the better way to reproduce the crash process.

This paper aims to examine the extent to which the top tether that is often neglected and leads to the inappropriate installations of CRS affects the injuries of child occupants aged 3 by the means of experimental methodology. In order to obtain the useful information, a testing scheme was devised and 4 tests with different set-ups were conducted. By comparison of test results, the influence of the most common inappropriate installation on the ability of CRS to protect child occupants can be discerned. The ability could be demonstrated by the safety performance of CRS and linked directly with the injury potential of child occupants.

\section{Methodology}

In order to ensure objectivity, universality and to reflect the real status of CRS quality, four CRS samples were bought randomly from a local market in China according to the requirements that the product should be forward facing ISOFIX CRS with top tether and belong to group I restraints suitable for 3-year-old child occupants. Testing scheme was devised to ascertain the relationship between injuries of child occupants aged 3 with the top tether of ISOFIX CRS in a frontal crash accident, for the most common incorrect or inappropriate installation lies in forgetting to connect the top tether to the anchorage. The crash tests were conducted using the existing UN Regulation No. 44 fixture and P series 3-year (P3) manikin by means of trolley of acceleration type. Compared with trolley of deceleration type, the acceleration one can ensure the consistency and precision of pulses with higher efficiency. But the acceleration curves were not limited to the regulation, i.e. the frontal impact pulses defined by the UN Regulation No. 44 and defined at will were both adopted. These pulses can be produced and adjusted to simulate and resemble the vehicle deceleration in the frontal crash by the trolley system. In total, two kinds of acceleration pulses produced by the trolley system were used to carry out the crash tests, one kind representing the typical abrupt deceleration of the vehicle in the form of the pulse specified by the regulation and the other kind representing the deceleration in extreme conditions.

\section{A Test Preparation}

Four independent tests were carried out, in which the accelerometer, the high-speed camera and the clay were used respectively to obtain the necessary information of acceleration, displacement and abdominal penetration. A sample of modelling clay was vertically connected to the front of the lumbar vertebrae by means of thin adhesive tape and gave indication of abdominal penetration. In tests, the modelling clay samples were of the same length and width as the lumbar spinal column, with the thickness of the samples being $25 \pm 2 \mathrm{~mm}$. Accelerations of the trolley and manikin would undergo CFC 60 and CFC 180 signal filtration respectively [37, 38]. Frequency class designated by the numbers 60 and 180, i.e., CFC 60 and CFC 180, indicated that the channel frequency responses lay within specified limits or were filtered using specified algorithms. Comparability of testing results and signalto-noise ratio were improved by processing signals in this way. 
As shown in Fig.1, the test was set-up by, firstly placing the P3 manikin so that the gap was between the rear of the manikin and CRS. Then the hinged board $2.5 \mathrm{~cm}$ thick and 6 $\mathrm{cm}$ wide and of length equal to the shoulder height was placed to follow as closely as possible the curvature of the restraint. Secondly, the belt used to restrain the manikin was pulled to a tension of $275 \mathrm{~N}$ with a deflection angle of $45^{\circ}$.

As tabulated in Table 1, the testing scheme devised contains four tests under different conditions and the set-ups. The CRS was installed to the test seat of the UN Regulation No. 44 fixture in accordance with the user manual, and the hinged board was removed. After completing the procedure, the ISOFIX and top tether were both connected to the anchorages separately in the first and the third tests, while only the ISOFIX was connected in the second and the fourth tests. In the first and second tests, the acceleration pulse defined by the regulation would be produced. In the third and fourth tests, the acceleration pulse defined at will but whose integrated value would be set in a proper range would be used. The procedure of preparation in each test was fixed except for the way in which CRS was connected to the test seat and the acceleration pulse adopted.

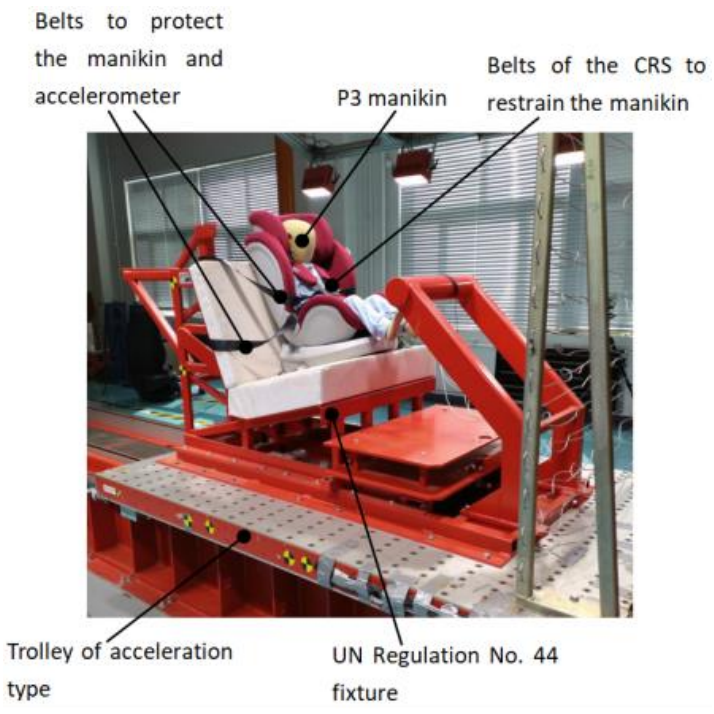

(a) Installation finished

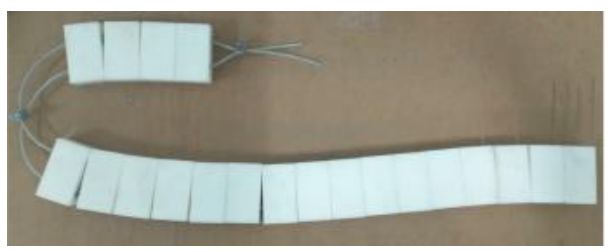

(b) The hinged board removed before a test

Fig. 1. Test setup: P3 manikin restrained in the CRS ready for test

\section{TABLE 1}

Testing scheme, conditions and the set-ups

\begin{tabular}{cccc}
\hline Test No. & $\begin{array}{c}\text { CRS } \\
\text { Installation } \\
\text { method }\end{array}$ & Parameters measured & Acceleration pulse \\
\hline 1 & $\begin{array}{c}\text { ISOFIX+top } \\
\text { tether }\end{array}$ & $\begin{array}{c}\text { Head displacement } \\
\text { Thorax acceleration } \\
\text { Abdomen penetration }\end{array}$ & $\begin{array}{c}\text { Frontal impact in UN Regulation No. } \\
44\end{array}$ \\
\hline 2 & ISOFIX & ditto & Frontal impact in UN Regulation No. \\
44
\end{tabular}

\section{B Injury Requirements}

According to the extent to which human body can endure the acceleration and the related regulation's specification, the resultant chest acceleration of the child shall not exceed $55 \mathrm{~g}$ except during periods whose sum does not exceed $3 \mathrm{~ms}$. The vertical component of the acceleration from the abdomen towards the head shall not exceed $30 \mathrm{~g}$ except during periods whose sum does not exceed $3 \mathrm{~ms}$ [38, 39, 40]. Once these requirements are met, the child occupant can be, theoretically, protected and the injuries to organs in the thorax are avoided.

As for the requirements of abdominal penetration, there shall be no visible signs of penetration of the modelling clay of the abdomen caused by any part of the restraining device. Once the penetration occurs, it means the abdomen of the child occupant has suffered severe injury in a real crash accident. One example of such a penetration is illustrated in Fig.2.

Requirements of manikin's head displacement are related with the type of CRS and the group to which the CRS belongs. Actually, most regulations' specifications on the displacement of manikin's head are almost the same especially in the values of displacement. And the specifications can be referred to as the norms to evaluate whether the displacement values have exceeded the range of safety. As a summary of the specifications mentioned, a figure used for fast evaluation of displacement was devised in this paper, and depicted in Fig. 3 $[38,39]$. As can be seen in Fig.3, the heavy line represents the evaluation boundary between forward facing CRS and rearward facing CRS, and the displacement boundary as well. The horizontal and vertical continuous thin lines indicate the displacement boundary that the head of the manikin should not exceed. The slant line stands for the common boundary of displacement. Cr line is defined in UN Regulation No. 44, and it is the origin for measurement, and measurement unit is $\mathrm{mm}$ in the figure. In the space, line $\mathrm{Cr}$ is coincident with the intersection line between the top plane of the seat on which the 
CRS is put and restrained and the front lane of the seat back. In the four tests, CRS used belongs to group I, so the values of front boundary and upper boundary should be $500 \mathrm{~mm}$ and $800 \mathrm{~mm}$ respectively.

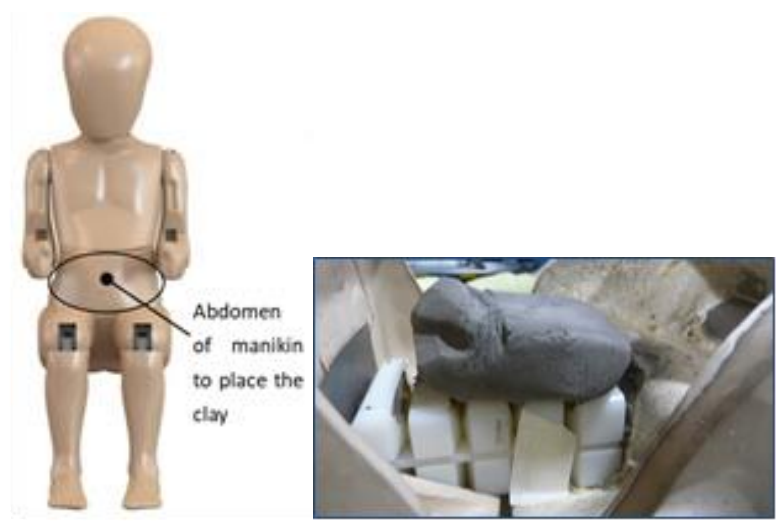

(a) P3 manikin

(b) Clay in the abdomen of P3 manikin

Fig. 2. Abdominal penetration of $\mathrm{P} 3$ manikin

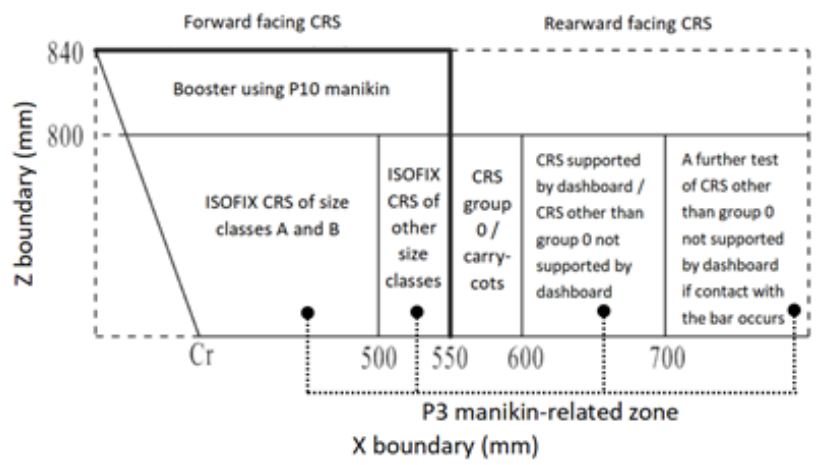

Fig. 3. Fast evaluation of displacement of manikin's head based on (WP.29, 2013; WP.29, 2014) regulations [38, 39]

\section{RESULTS}

After test preparation, four tests were carried out sequentially using the acceleration type trolley according to the testing scheme. Given the target curve of the acceleration, the trolley produced the actual pulses in the tests. The actual pulse could be deemed as the equivalent of the deceleration that the vehicle would undergo in a frontal crash accident. As depicted in Fig.4, the two acceleration pulses were produced by the trolley according to UN Regulation No. 44 in the dynamic tests, and met the requirement of the regulation. The pulses in Fig. 5 produced by the trolley did not necessarily meet any requirement of the regulations related with the safety of CRS, and could be seen as the proper simulation of the frontal crash too. Target curves employed in the third and fourth tests were defined at will and were used as the guide for the trolley to produce the actual pulses shown in Fig.5. The peak accelerations can be of $75 \mathrm{~g}$ or greater in magnitude and the pulses themselves simulate the automotive crashes under extreme conditions. Besides CRS tends to fail to work when the worst happens, so to some extent it is more severe, representative and objective to conduct the testing scheme using the pulses of this kind as the simulation of the real accelerations.

The accelerations of the manikin's chest measured in the tests when the ISOFIX attachment and top tether are both connected and when the top tether is not connected with only ISOFIX attachment being connected differ greatly in magnitude, for the lack of the upper fastening point is easy to cause the unstable status of CRS. The differences in $\mathrm{X}, \mathrm{Y}$ and $\mathrm{Z}$ directions between the comparative tests and the resultant accelerations compare are illustrated in Fig.6, Fig.7, Fig.8 and Fig.9 respectively, which are the results of dynamic tests carried out according to related regulations. In addition to differences between chest accelerations, it is also noteworthy that slight visible signs of abdominal penetration are found, and head displacements are also very close to the limits in the second test, and the phenomena are usually brought about by the unstable status of CRS in a dynamic test.

However, the third and fourth tests that are not conducted according to related regulations and whose acceleration curves are set at will and are more severe than the ones specified by regulations returned completely different results. In the third dynamic test, the resultant acceleration and the vertical acceleration both satisfy the requirements and the test results are partly qualified due to the good protection of CRS for the child occupant, as shown in Fig.10, although the process has been set under severe conditions. Therefore, it can be inferred that the appropriate installation of CRS is of importance to improve the safety. The top tether of ECRS works as an important anti-rotation device and provides the third fastening point for ECRS installation, thus ensuring the stable status in which the child occupant can get necessary protection in a crash. Without the upper fastening point provided by the tether, damages usually inevitably occur to the CRS in extreme or severe conditions, and make CRS fail to take effect. Fig.11 displays the damaged CRS in the fourth dynamic test. In fact, the damage was caused by the lack of the upper fastening point provided by top tether and the consequent bending moment in large-magnitude. The CRS did not fall off the trolley because of the belts that had been fastened to protect the manikin and the accelerometer in advance.

Detailed testing results and values are illustrated in Table.2. Results of the first and second tests are both qualified to a great extent, while the head displacement exceeds the permitted range in the third test with the accelerations meeting 
the requirements. But in the fourth test, complete failure of CRS occurs and no criterion is satisfied.

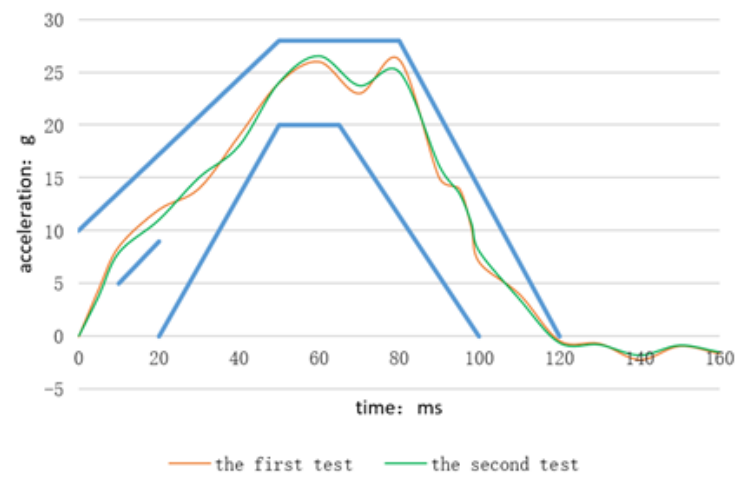

Fig. 4. Acceleration pulses of the trolley employed in the first and second tests

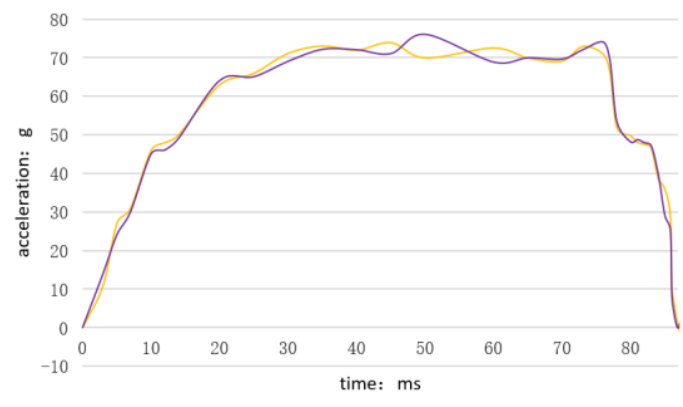

the third test

Fig. 5. Acceleration pulses of the trolley employed in the third and fourth tests

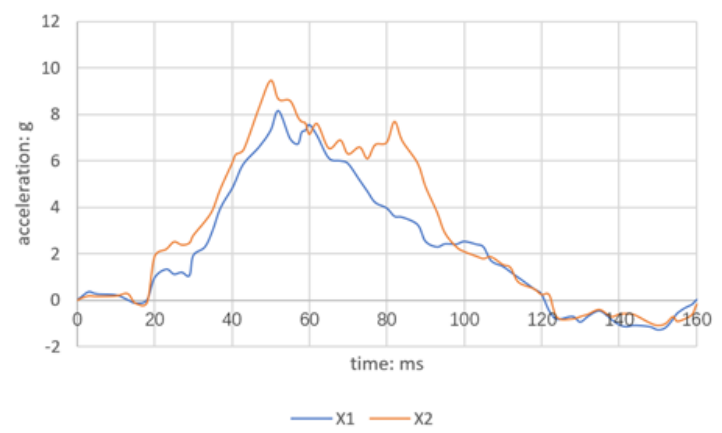

Fig. 6. Chest accelerations of the manikin in X direction in the first and second tests

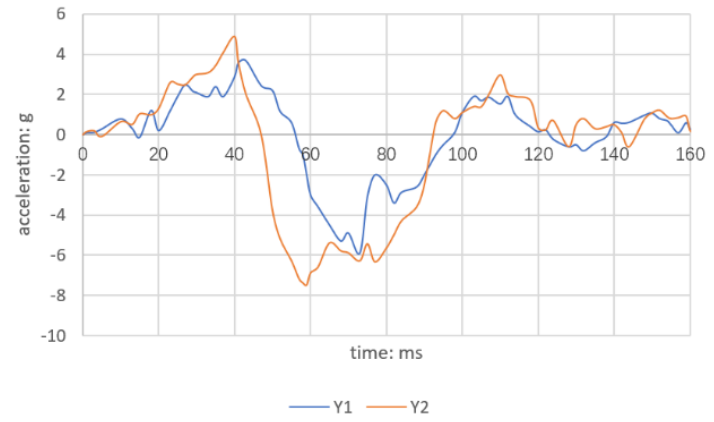

Fig. 7. Chest accelerations of the manikin in $\mathrm{Y}$ direction in the first and second tests

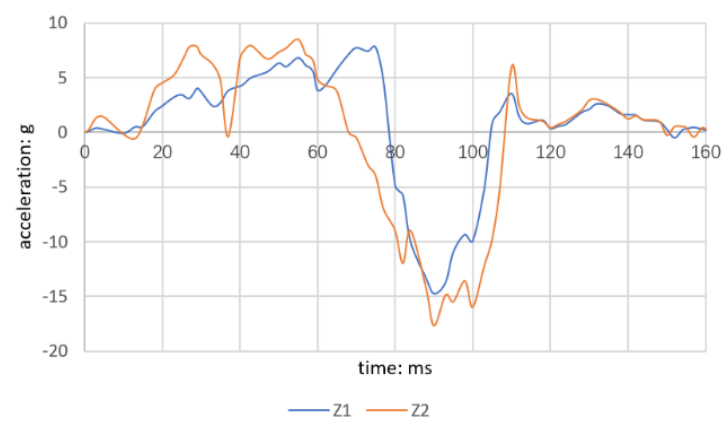

Fig. 8. Chest accelerations of the manikin in $\mathrm{Z}$ direction in the first and second tests

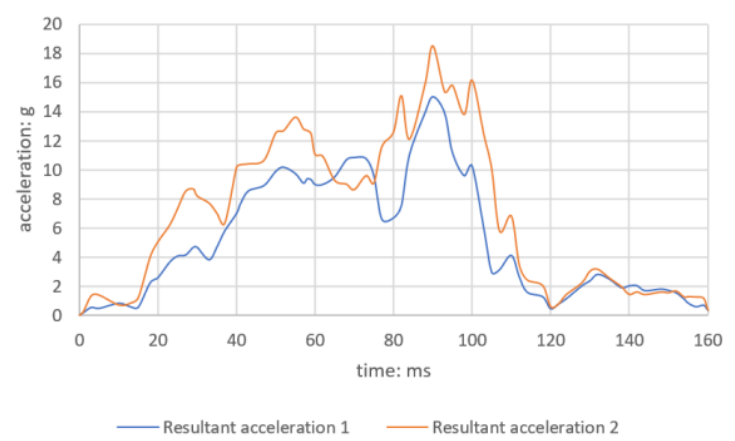

Fig. 9. Resultant accelerations of the manikin's chest in the first and second tests 


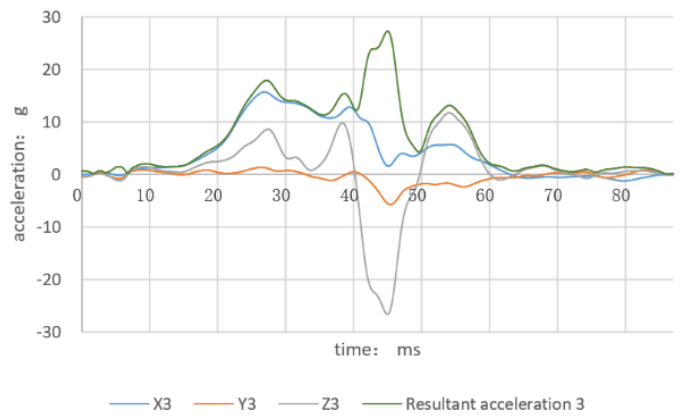

Fig. 10. Chest accelerations of the manikin in the third test

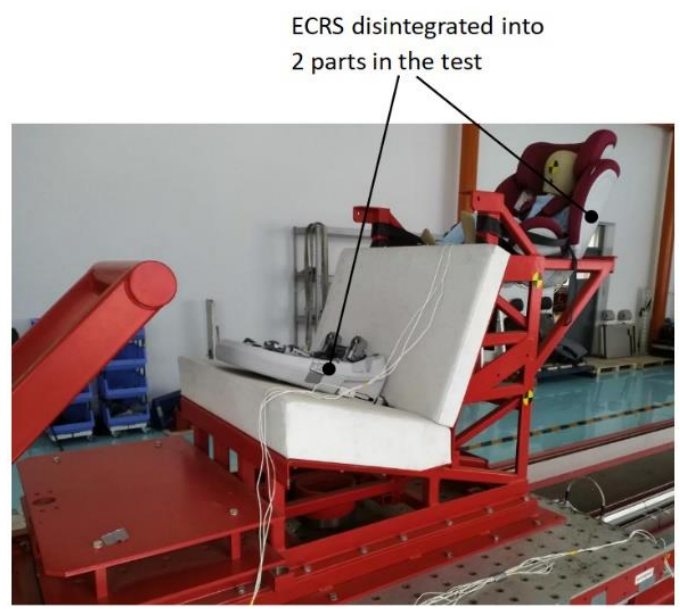

Fig. 11. Damaged ECRS in the fourth test

TABLE 2

Testing results

\begin{tabular}{cccc}
\hline $\begin{array}{c}\text { Test } \\
\text { No. }\end{array}$ & Peak acceleration of thorax & Abdominal penetration & Head displacement \\
\hline \multirow{2}{*}{1} & Resultant: $15.0 \mathrm{~g}$ & no visible signs of & Front: $382 \mathrm{~mm}$ \\
& Vertical: $-14.7 \mathrm{~g}$ & penetration & Upper: $612 \mathrm{~mm}$ \\
\hline \multirow{2}{*}{2} & Resultant: $18.5 \mathrm{~g}$ & slight visible signs of & Front: $495 \mathrm{~mm}$ \\
& Vertical: $-17.7 \mathrm{~g}$ & penetration & Upper: $767 \mathrm{~mm}$ \\
\hline \multirow{2}{*}{3} & Resultant: $27.3 \mathrm{~g}$ & slight visible signs of & Front: $596 \mathrm{~mm}$ \\
& Vertical: $-26.9 \mathrm{~g}$ & penetration & Upper: $833 \mathrm{~mm}$ \\
\hline 4 & CRS failure & CRS failure & CRS failure \\
\hline
\end{tabular}

\section{DISCUSSION}

The results of the dynamic tests reflect that the top tether as the anti-rotation device plays an important role in improving the safety performance of ECRS in frontal crash accidents. Thorax accelerations, abdominal penetration and head displacements of child occupants are directly related with the installation method. According to the research, inappropriate installation such as the neglect or wrong use of top tether most common in daily use can impair the ability of ECRS to resist the abrupt deceleration and to absorb the dynamic energy that will otherwise be transmitted to child occupants and result in injuries during a frontal vehicle crash.

Trends exist that peak accelerations of child occupant's thorax decrease with the proper use of top tether in a crash, and as the additional fastening point, the tether can restrain the CRS effectively from rotation and deformation that usually make the child suffer from large accelerations and abdominal penetration, and cause the situation in which head displacements exceed the permitted range, as displayed in Fig.6-Fig.11. Hence, it is recommended that top tether should be used properly no matter what magnitude of the automotive deceleration in a crash accident can be.

Further research is needed to stipulate the preventive measures for avoiding inappropriate installation of any kind. Legislation, standards, specifications and technical regulations could be amended and revised in time to adapt to new changes in the use of CRS. Being a significant factor in resisting the rotation of ECRS during a frontal crash, the top tether connection should be not ignored. Steps could be taken to increase the public awareness of these issues, thus reducing chances of inappropriate installations of ECRS with top tether.

\section{CONCLUSION}

It can be concluded that top tether affects the accelerations of thorax, abdominal penetration and head displacements of child occupants aged 3 by devising the testing scheme and comparing the test results of four dynamic tests conducted in different experimental set-ups. Proper use of top tether in the process of installation can reduce the risk of functional failure of CRS and enhance its ability to satisfy the safety criteria, thus improving the safety performance. The additional fastening point provided by top tether is necessary and able to ensure that CRS works normally and is in the stable status during a frontal crash. Theoretically, appropriate installation of ECRS with top tether will bring about fewer injury potentials. The inappropriate installation will not only give rise to injury potential, but may cause severe damages even to CRS itself under extreme conditions. Therefore, connecting top tether to the anchor point should be deemed as an essential prerequisite before seating a child into the CRS.

With the emergence of ECRS with anti-rotation device such as the top tether, convenience, comfort and safety performance of CRS become more obvious, thus making products of this kind have a growing tendency and possibility of substituting the traditional CRS installed by the seatbelt. Recently tremendous progress has been made in the fields of CRS designing, manufacturing, utilization, standardization and testing, especially in Europe and North America, whose technical standards related to passive safety are in the lead 
and can be a good reference in formulating standards of the same kind [4, 38, 39, 41]. China has the larger quantity of children from newborn to aged 10 than most other countries, while usage of CRS remains even low because of many factors among which the complexity in CRS installation is a noteworthy aspect and related with the wrong use of CRS to some extent [42]. Meanwhile inappropriate installation exists widely and consequently leads to many injuries and fatalities that should have been avoided in China too. Measures should be taken to tackle the problem of CRS inappropriate installation, and make it easy to check the status of CRS in use at any time before and during driving. On the one hand, improving public awareness and mechanisms of providing safety information to the public can contribute to minimizing inappropriate installations of CRS and fundamentally ameliorate the situation in which the step of connecting the top tether to the anchor is omitted consciously or unconsciously. On the other hand, technical advances in industry support more emergence of special devices used to prevent neglect or inappropriate use of passive safety devices that include CRS and other mechanical and electrical mechanisms, e.g., seatbelt, airbag, seat, etc. Various devices such as seatbelt reminder used for reminding occupants of using seatbelt have been long used and proved effective in discerning and preventing the incorrect use of safety devices, e.g., the failure of tongue's connection to the buckle, and similar devices can be designed and utilized to achieve the same effect for CRS installation [43]. Besides, the optimization of CRS structure and the proper layout of parts can also be taken into consideration, as a proper way, to eliminate risks of inappropriate installations [44, 45]. Efficient joint-action mechanism of industry, research institution, university, inspection organization, government and end users should be established to build the system in which any risk of designing, manufacturing, inspection and using related with CRS can be considered, discerned and avoided in terms of sources.

Finally, in view of the injury potential of child occupants aged 3 brought about by inappropriate installation of ECRS with top tether in a frontal crash accident, aspects involved in the process should be emphasized. The influence of top tether upon the ability of CRS to protect child occupants from injuries has been ascertained based on the testing scheme including four comparison tests, targeted methods can then be devised to deal with follow-up issues.

\section{REFERENCES}

[1] E. P. Elliott, A. C. Hariramani, and J. Ansiaux, "Child Passenger Safety," Physician Assist. Clin., vol. 1, no. 4, pp. 525-540, 2016, doi: 10.1016/j.cpha.2016.05.001.
[2] S. S. M. Chang, R. C. A. Symons, and J. Ozanne-Smith, "Child road traffic injury mortality in Victoria, Australia (0-14 years), the need for targeted action," Injury, vol. 49, no. 3, pp. $604-612,2018$, doi: 10.1016/j.injury.2017.12.018.

[3] T. Kuska and C. Rush, "Issues and trends in child passenger safety in the United States and Canada," Int. J. Trauma Nurs., vol. 7, no. 4, pp. 137-141, 2001, doi: 10.1067/mtn.2001.118969.

[4] M. Roynard, P. Silverans, Y. Casteels, and P. Lesire, "National roadside survey of child restraint system use in Belgium," Accid. Anal. Prev., vol. 62, pp. 369-376, 2014, doi: 10.1016/j.aap.2013.08.021.

[5] A. Akhavan Rezayat et al., "Child injury mortality in Iran: A systematic review and meta-analysis," J. Transp. Heal., vol. 16, p. 100816, 2020, doi: 10.1016/j.jth.2019.100816.

[6] G. Lee, C. N. Pope, A. Nwosu, L. B. McKenzie, and M. Zhu, "Child passenger fatality: Child restraint system usage and contributing factors among the youngest passengers from 2011 to 2015," J. Safety Res., vol. 70, pp. 3338, 2019, doi: 10.1016/j.jsr.2019.04.001.

[7] S. Bendak and K. Alkhaledi, "Child restraint system use in the United Arab Emirates," Transp. Res. Part F Traffic Psychol. Behav., vol. 51, pp. 65-72, 2017, doi: 10.1016/j.trf.2017.09.001.

[8] A. Chaudhry, I. Sanaullah, B. Z. Malik, and A. A. Klair, "An investigation of awareness, perceptions, and usage of child car seats in Pakistan," J. Transp. Heal., vol. 13, pp. $247 \quad-\quad 258,2019$, doi:10.1016/j.jth.2019.05.001.

[9] J. Ignacio Nazif-Muñoz, A. Nandi, and M. Ruiz-Casares, "Impact of child restraint policies on child occupant fatalities and injuries in Chile and its regions: An interrupted time-series study," Accid. Anal. Prev., vol. 120, pp. 38-45, 2018, doi: 10.1016/j.aap.2018.07.028.

[10] E. F. Sam, "Don't learn safety by accident: A survey of child safety restraint usage among drivers in Dansoman, Accra," J. Transp. Heal., vol. 2, no. 2, pp. 160-165, 2015, doi: 10.1016/j.jth.2014.08.003.

[11] E. N. Aidoo, W. Ackaah, S. K. Appiah, E. K. Appiah, J. Addae, and H. Alhassan, "A bivariate probit analysis of child passenger's sitting behaviour and restraint use in motor vehicle," Accid. Anal. Prev., vol. 129, pp. 225229, 2019, doi: 10.1016/j.aap.2019.05.022.

[12] J. I. Nazif-Muñoz, J. Falconer, and A. Gong, "Are child passenger fatalities and child passenger severe injuries 
equally affected by child restraint legislation? The case of Chile," Int. J. Inj. Contr. Saf. Promot., vol. 24, no. 4, pp. $501 \quad$ - 509, Oct. 2017, doi: 10.1080/17457300.2016.1278236.

[13] J. I. Nazif-Munoz and N. Nikolic "The effectiveness of child restraint and seat belt legislation in reducing child injuries: The case of Serbia," Traffic Inj. Prev., vol. 19, no. $\quad$ sup1, pp. S7 - S14, Feb. 2018, doi: 10.1080/15389588.2017.1387254.

[14] J. Shanthosh et al., "Effectiveness of child restraint legislation to reduce motor vehicle related serious injuries and fatalities: A national interrupted time series analysis," Accid. Anal. Prev., vol. 142, p. 105553, 2020, doi: 10.1016/j.aap.2020.105553.

[15] S. Nakahara, M. Ichikawa, and Y. Nakajima, "Effects of Increasing Child Restraint Use in Reducing Occupant Injuries Among Children Aged 0-5 Years in Japan,"

Traffic Inj. Prev., vol. 16, no. 1, pp. 55-61, Jan. 2015, doi: 10.1080/15389588.2014.897698.

[16] S. L. Bachman, G. A. Salzman, R. V Burke, H. Arbogast, P. Ruiz, and J. S. Upperman, "Observed child restraint misuse in a large, urban community: Results from three years of inspection events," J. Safety Res., vol. 56, pp. 17-22, 2016, doi: 10.1016/j.jsr.2015.11.005.

[17] K. D. Klinich et al., "Effects of child restraint system features on installation errors," Appl. Ergon., vol. 45, no.

2, Part B, pp. 270 - 277, 2014, doi: 10.1016/j.apergo.2013.04.005.

[18] J. S. Jermakian et al., "Factors affecting tether use and correct use in child restraint installations," J. Safety Res., vol. 51, pp. $99-108, \quad 2014$, doi: 10.1016/j.jsr.2014.09.011.

[19] A. H. Eichelberger, L. E. Decina, J. S. Jermakian, and A. T. McCartt, "Use of top tethers with forward-facing child restraints: Observations and driver interviews," $J$. Safety Res., vol. 48, pp. 71 - 76, 2014, doi: 10.1016/j.jsr.2013.11.002.

[20] Skjerven-Martinsen, P. A. Naess, T. B. Hansen, T. Staff, and A. Stray-Pedersen, "Observational study of child restraining practice on Norwegian high-speed roads: Restraint misuse poses a major threat to child passenger safety," Accid. Anal. Prev., vol. 59, pp. 479-486, 2013, doi: 10.1016/j.aap.2013.07.023.

[21] J. Brown, C. F. Finch, J. Hatfield, and L. E. Bilston, "Child Restraint Fitting Stations reduce incorrect restraint use among child occupants," Accid. Anal. Prev., vol. 43, no. 3, pp. 1128 - 1133, 2011, doi: 10.1016/j.aap.2010.12.021.

[22] D. C. Schwebel, M. A. Tillman, M. Crew, M. Muller, and A. Johnston, "Using interactive virtual presence to support accurate installation of child restraints: Efficacy and parental perceptions," J. Safety Res., vol. 62, pp. 235-243, 2017, doi: 10.1016/j.jsr.2017.06.018.

[23] K. Tessier, "Effectiveness of hands-on education for correct child restraint use by parents," Accid. Anal. Prev., vol. 42, no. 4, pp. 1041 - 1047, 2010, doi: 10.1016/j.aap.2009.12.011.

[24] S. M. Beeman, A. R. Kemper, M. L. Madigan, C. T. Franck, and S. C. Loftus, "Occupant kinematics in lowspeed frontal sled tests: Human volunteers, Hybrid III ATD, and PMHS." Accid. Anal. Prev., vol. 47, 128-139, 2012. doi: 10.1016/j.aap.2012.01.016.

[25] D. S. Bhalerao, S. A. Kale, K. D. Sapate, and A. V. Mannikar, "Finite elemental analysis of pull and release trolley for conducting vehicle crash tests," Int. J. Eng. Tech., vol. 8, no. 5, pp. 2115-2120, 2016.

[26] R. K. Myers, L. Lombardi, M. R. Pfeiffer, M. R. Zonfrillo, and A. E. Curry, "Child restraint use and hospitalreported injuries among crash-involved child passengers," Traffic Inj. Prev., pp. 1-2, Nov. 2020, doi: 10.1080/15389588.2020.1829931.

[27] B. L. Findlay, A. Melucci, V. Dombrovskiy, J. Pierre, and Y.-H. Lee, "Children after motor vehicle crashes: Restraint utilization and injury severity," J. Pediatr. Surg., vol. 54, no. 7, pp. $1411-1415$, 2019, doi: 10.1016/j.jpedsurg.2018.10.046.

[28] C. M. Harbaugh et al., "Evaluating the 'cushion effect' among children in frontal motor vehicle crashes," $\mathrm{J} . \mathrm{Pe}$ diatr. Surg., vol. 53, no. 5, pp. 1033-1036, 2018, doi: 10.1016/j.jpedsurg.2018.02.042.

[29] A. Hall et al., "Barriers to correct child restraint use: A qualitative study of child restraint users and their needs," Saf. Sci., vol. 109, pp. 186 - 194, 2018, doi: 10.1016/j.ssci.2018.05.017.

[30] L. Niu, Y.-M. Gao, Y. Tian, and S.-M. Pan, "Safety awareness and use of child safety seats among parents after the legislation in Shanghai," Chinese J. Traumatol., vol. 22, no. 2, pp. 85 - 87, 2019, doi: 10.1016/j.cjtee.2018.08.005.

[31] D. S. Usami, L. Persia, and V. Sgarra, "Determinants Of The Use Of Safety Restraint Systems In Italy," Transp. Res. Procedia, vol. 45, pp. $143-152$, 2020, doi: 10.1016/j.trpro.2020.03.001. 
[32] S. Yan et al., "Assessing an App-Based Child Restraint System Use Intervention in China: An RCT," Am. J. Prev. Med., vol. 59, no. 3, pp. e141-e147, 2020, doi: 10.1016/j.amepre.2020.02.003.

[33] T. Kapoor et al., "A numerical investigation into the effect of CRS misuse on the injury potential of children in frontal and side impact crashes," Accid. Anal. Prev., vol. 43, no. 4, pp. 1438 - 1450, 2011, doi: 10.1016/j.aap.2011.02.022.

[34] Y. Meng and C. Untaroiu, "Numerical investigation of occupant injury risks in car-to-end terminal crashes using dummy-based injury criteria and vehicle-based crash severity metrics," Accid. Anal. Prev., vol. 145, p. 105700, 2020, doi: 10.1016/j.aap.2020.105700.

[35] L. Tang, J. Zheng, and J. Hu, “A numerical investigation of factors affecting lumbar spine injuries in frontal crashes," Accid. Anal. Prev., vol. 136, p. 105400, 2020, doi: 10.1016/j.aap.2019.105400.

[36] D. Bruski et al., "Experimental and numerical analysis of the modified TB32 crash tests of the cable barrier system," Eng. Fail. Anal., vol. 104, pp. 227-246, 2019, doi: 10.1016/j.engfailanal.2019.05.023.

[37] X. R. Zhang, Y. H. Shi, "Simulation and experiment study on the deviation influence factors of dynamic collision test for child safety seat," Int. J. Crash., vol.0:0, 2019, pp. 1-12.

[38] World Forum for Harmonization of Vehicle Regulations(WP.29), "Uniform provisions concerning the approval of restraining devices for child occupants of power-driven vehicles ('Child Restraint Systems')". 2014, Available at:

https://unece.org/transport/vehicle-regulationswp29/standards/addenda-1958-agreement-regulations121-140.

[39] World Forum for Harmonization of Vehicle Regulations(WP.29), "Uniform provisions concerning the approval of enhanced Child Restraint Systems used on board of motor vehicles (ECRS)". 2013, Available at: https://unece.org/transport/vehicle-regulationswp29/standards/addenda-1958-agreement-regulations41-60.

[40] B. D. Graaf, and W. V. Weperen, "The retention of balance: an exploratory study into the limits of acceleration the human body can withstand without losing equilibrium," Human Factors, vol. 39, no. 1, pp. 111-118, 1997.

[41] T. Kuska, and C. Rush, "Issues and trends in child passenger safety in the United States and Canada. Int. J. Trauma. Nursing. " vol. 7, no. 4, pp. 137-141, 2001, doi: 10.1067/mtn.2001.118969
[42] K. Omari and O. Baron-Epel, "Low rates of child restraint system use in cars may be due to fatalistic beliefs and other factors," Transp. Res. Part F Traffic Psychol. Behav., vol. 16, pp. 53 - 59, 2013, doi: 10.1016/j.trf.2012.08.010.

[43] W. A. Good, "Child seat restraint alarm system," 2010, US.

[44] J. A. Mansfield, Y. N. Zaragoza-Rivera, G. H. Baker, and J. H. Bolte, "Evaluation of interventions to make top tether hardware more visible during child restraint system (CRS) installations," Traffic Inj. Prev., vol. 20, no.

5, pp. 534 - 539, Jul. 2019, doi: 10.1080/15389588.2019.1618849.

[45] K. Stylidis, E. Al-Saidi, A. T. Erinjery, L. Lindkvist, C. Wickman, and R. Söderberg, "Design of the top tether component for the premium car market segment: Case study of Volvo Cars," Procedia CIRP, vol. 91, pp. 146151, 2020, doi: 10.1016/j.procir.2020.02.160.

Zhe Wei is a senior engineer in National Quality Supervision and Inspection Centre for Engineering Machinery affiliated to China Academy of Machinery Science and Technology. He obtained the B. Sc and M. Sc in 2007 and in 2010 respectively. His research field is related with vehicle's passive safety now. As the first author and the first inventor, he has more than 20 publications and 5 authorized patents. Meanwhile, he owns the premium membership of Chinese Society of Agricultural Machinery and is the committee member of SAC/TC 240. 